En definitiva, el trabajo muestra que una ensetianza de la Biología coherente con la Naturaleza de la ciencia y concebido como un cambio conceptual y metodológico, favorece una familiarización efectiva con la metodología cientifica, y fomenta una actitud positiva hacia la ciencia y su aprendizaje.

LA EVALUACION DE LA BIOLOGIA EN LA SEGUNDA ETAPA DE E.G.B. (Tesis Doctural)

Director: Dr. Adalberto Ferrández

Doctoranda: Ana $M^{a}$ Geli de Ciurana (Escuela Universitaria de Magisterio Girona)

Facultad de Letras

Universided Aulónoma de Barcelona. Junio 1986.

En el momento actual asistimos a una profunda transformacion del sistema educativo en un gran número de paises. En España, superada ya la fase de expansión cuantitativa, los objetivos finales de la renovación son: la mejora de la calidad de la enseñanza y la disminución del fracaso escolar. La consecución de estos objetivos exige un profundo conocimiento de la realidad escolar para poder disenar nuevos programas que resulten viables y eficaces.

Por otra parte el trabajo pedagógico no puede quedar reducido a una serie de observaciones que nos faciliten una interpretación intuitiva y lógica. Es preciso aplicar a la investigación educat:va las metodologlas de carácter cuantitativo que nos ofrezcan informaciones significativas de los numerosos aspectos del proceso docente.

En este marco hemos analizado los niveles de instrucción que presentan 1721 alumnos de $8^{\circ}$ curso de EGB en la ma. teria de Biología, asi como los patrones de calificación utilizados en 51 escuelas de la provincia de Gerona y su relación con la organización escolar del centro.

Para ello se han diseñado y utilizado instrumentos de exploración diagnós. tica que nos han informado de la incidencia de las distintas variables anali. zadas en los centros de EGB.

E! analisis cualitativo del nivel de instrucción alcanzado se ha realizado mediante diagramas de respuestas al test en cada grupo de alumnos, por el sistema de nube de puntos y el análisis cuantitativo se basa en una completa descripción estadística de cada centro, con elaboración de una ficha escolar y representación gráfica de los resultados, mediante un programa de ordenador elaborado exprofeso. Para la inves tigación de los factores subyacentes hemos realizado el programa BMDP Statistical Software de la Universidad de California en su versión de 1985 que nos ha permitido aplicar numerosas pruebas de correlación, test de $\mathbf{X}^{2}$ y análisis factorial de la varizanza.

Las conclusiones obtenidas son: la mayoria de alumnos no alcanzan los niveles minimos exigidos, ni aun en aquellos casos que superan los controles y pruebas a que son sometidos por sus profesores. Estos, a su vez, carecen de medios que les permitan establecer comparaciones objetivas entre el ren dimiento de sus alumnos y el rendimiento teórico esperado.

Por todo ello destacamos la necesidad de que la evaluación que se realiza en las escuelas sea considerada en toda su importancia, dado su papel diagnóstico en el aprendizaje de los alumnos y en el funcionamiento y eficacia del mo delo de instrucción en todos sus aspectos.

Para ello hemos presentado diversas propuestas que tienden a mejorar este aspecto $\tan$ necesario del proceso docente.

\title{
RESEÑAS DE CONGRESOS Y JORNADAS
}

Incluimos a continuación dos reseñas recibidas del "Primer Symposium sobre l'Ensenyament de les Ciències $\mathrm{Na}$ turals" celebrado en Vic (Barcelona) en marzo 1986. Aunque en general esta duplicidad no tiene sentido hemos creído interesante, por una vez, mostrar dos versiones distintas de un mismo evento.

PRIMER SYMPÖSIUM SOBRE L'ENSENYAMENT DE LES CIENCIES NATURALS. Vic (Barcelona) Marzo 1986.

Organizado por la Escuela Universitaria Balmes, de Vic (Barcelona), tuvo lugar en dicha ciudad durante los días del 12 al 15 de Marzo de 1986, el Primer Symposium sobre la enseñanza de las
Ciencias Naturales, como manifestación de la preocupación, vitalidad y empuje existente en la comarca de Osona por la enseñanza de esta asignatura y todo lo que con ella se relaciona.

La importancia de la convocatoria de esta reunión radicó en ser la primera que se realizaba en lengua catalana, con io que ello significa de normalización de una lengua, y en hacer su llamada a los enseñantes que tienen un entorno común. En estos momentos estamos presenciando una excesiva of erta de congresos de didáctica, al menos en Ciencias Naturales, con las mismas características en todos ellos: una generalidad en la que todo cabe. El Symposium de Vic, se presentaba restringido a un ámbito concreto, sobre el cual los ensetantes podian intercambiar sus trabajos y experiencias.

El interés de estas Jornadas ha consistido, en la altura y concreción de las Comunicaciones of recidas por los asis. tentes, $y$ en la perfecta organización de la misma.

Las aportaciones de los congresistas se dividieron en tres secciones:

- Actividades fuera de la escuela. - Los contenidos y su didáctica. - Trabajos interdisciplinares.

Cada una de ellas subdividida en dos apartados, comunicaciones orales y posters.

Las actividades fuera del aula fue e marco donde se presentó, por un lado,

la ya larga experiencia que existe en $\mathrm{Ca}$ - 
talunya en temas de Escola de Natura, of reciendo no sólo sus realizaciones, sino el punto de reflexión en el que se en. cuentran Escolas como «la Vola», «el Corredor", "la Culla», "Tortebonica", "Can Girona", etc. Y por otro lado, las investigaciones y trabajos que los alumnos acometen fuera de clase, desde el estudio de la Genética en el Huerto escolar o en la Granja con conejos, hasta los estudios medio ambientales del bosque, el rio, la sierra, etc. pasando por los árboles y aves de la ciudad, e inciuso dando a conocer los recursos didácticos que el Museo de Zoologia de Barcelona o la zona volcánica de Olot ofrecen. Posters sobre el lago de Ban. yoles, el palomo, o los moluscos de las playas, entre otros, indicaban concretamente las actividades didácticas que se pueden flevar a término con los alumnos.

Los contenidos y su didáctica fue el epígrafe que mayor número acogió, todos ellos preosupados, no sólo por los contenidos, sino por la metodologia a emplear, por las motivaciones del alumnado, y por la creación de actitudes y aptizudes cientificas. Asi, propuestas razonadas de cursos enteros o partes importantes a introducir en los curricula, experiencias concretas, metodologias diferentes a las tradicionales, estudios bibliométricos, del desarrollo de ciertas aptitudes científicas con la edad, etc., fueron desfilando logrando el in: terés de los asistentes. En este aparta. do cabe senalar dos temas importantes por su incipiente implantación en los centros educativos, el uso de los orde. nadores como recurso didáctico y la utilización de los juegos para explicar procesos biológicos o hacer simulaciones, especialmente en Ecologia.

La sección de trabajos interdisciplina. res, aunque tuvo menos aportaciones, no por ello estuvo falta de interés. El agua se mostró como el más importante núcleo aglutinador de los objetivos pedagógicos de diversas áreas, a tenor del número de experiencias presentadas, pero también desde otros temas se ofre cieron trabajos que pueden servir de modelo: el huerto escolar, la nutrición o la ordenación territorial, son puntos importantes para trabajar con el alumno desde un punto de vista interdisciplinar. La comunicación presentada sobre la detección de errores conceptuales en Ciencias Naturales, es un traba* jo interdisciplinar pero de profesores, los cuales, además de poner a punto un método, muestran sus interesantes resultados.
La organización de las Jomadas rayó la perfección, muestra de ello son los itinerarios que alli se hicieron, la publicación con celeridad de tas comunicaciones admitidas y la presentación de «Set itineraris per la Catalunya Cen. tral», que aunque de autores diferentes, mantienen todos una metodología común. Para que no se escapara detaIle, $y$ en homenaje a los hermanos Vilarrúbia, importantes naturalistas de la Plana de Vic, han editado, con ocasión de este Primer Symposium, un trabajo de Antoni Vilarrúbia, denominado "Les Zoocecidies de les plantes de Catalunyan.

La trascendencia de este Congreso se verá reflejada, no sólo de inmediato en las aulas, sino dentro de dos años, cuando se vuelva a repetir.

V. Gavidia

\section{PRIMER SYMPÒSIUM SOBRE} L'ENSENYAMENT DE LES CIĖN. CIES NATURALS. Vic (Barcelona) Marc 1986

Els dies $12,13,14 \mathrm{i} 15$ del proppassat mes de març se cejebrà a l'Escola Universitària Balmes de Vic el Primer Symposium sobre l'Ensenyament de les Ciències Naturals, on s'hi aplegaren 519 professionals.

Donat que es tracta d'un Primer Sympósium, hom considera oportú es. mentar aqui, també, quina ha estat la gènesi que ha possibilitat la seva realització. Un grup d'ensenyants de Ciències Naturals, que cobria tots els nivells educatius, senti la necessitat de comunicació viva i bescanvi d'experiències entre els professionals de l'ambit; a fi de poder-ho dur a terme s'adreçà tot oferin la proposta d'organització del sympositum- a aquelles institucions implicades en la formació inicial i permanent dels ensenyants: Escoles de Mestres d'arreu del Principat, ICE de les Universitats de Barcelona, Facultats de Biologia i Geologia de la Universitat de Barcelona i la Universitat Autonoma de Barcelona, Col-legis de Llicenciats i de Biòlegs i Moviment de Renovació $P$ edagògica de Catalunya; aques. tes es constituïren en Comité Organitzador del Sympòsium, amb el compro mis de vetllar per la seva continuïtat.

Els objectius de fons d'aquest Primer Sympòsium foren bàsicament dos:

a) Intentar fixar una trobada tempo- ral de tots els ensenyants implicats en la tasca de donar a conèixer i de fer viure els elements naturals que configuren un medi.

b) Posar a la llum tots aquells treballs, normalment silenciats i restringits a petits nuclis, que no disposen de mitjans de difusió; trebalis que d'altra banda poden ser tan interessants com els altres.

En síntesi, es pretenia potenciar la feina realitzada en l'ensenyament diari.

L'Acte inaugural fou presidit pel Director General d'Universitats, Dr. Ramon Parés, en representació del Conseller d'Ensenyament de la Generalitat de Ca. talunya, i el Sympòsium s'estructurà d'acord amb:

- Tres ponències centrais:

1. "El treball de camp", a càrrec d'en Paul Croft del Field Studies Council de Shrewsbury (Anglaterra), que presentà «L'experiència anglesa a les escoles de naturas, i Anna Agenjo, Martí Boa$\mathrm{da}$ i Jordi Miralles del Servei de Parcs Naturals de la Diputació de Barcelona, que tractaren "L'educació ambiental en els espais protegits».

2. "La interdisciplinarietat», ponents: Narcís Prat i Josep Ninot, nivell universitari. Pilar Figueres i Carme Esplugues, nivell ensenyament secundari. Neus Sanmarti i Aurora Maquinay, nivell EGB.

3. "Continguts i la seva didàctica: les Ciències Naturals des de la reforma del cicle Superior de l'EGB i el primer cicle de l'ensenyament secundaris, ponents: Antoni Dominguez, Marina Llorens, Carme López i Roser Pintó (G.O.E. - Generalitat de Catalunya).

- 50 Comunicaciones orals i 12 comunicacions póster, repartides entre els tres nuclis tematics; els resums de les quals es recopilaren en el llibre d'Actes del Symposium que es lliura als assistents.

4. Taules Rodones sobre els temes: "Escoles de Natura; Metodologia perspectives», "Museus: utilitat $j$ utilitzación, «El col-leccionisme d'elements d'un medi natural», «L'hort i l'enseryamenty.

- 4 Grups de treballs sobre: «Didàctica de les Ciències Naturals a les escoles de mestres», "Paper de les EATP'S de Naturals al Batxillerat", "L'hort a l'escola" $i$ "Escoles de natura".

- Presentació de materials àudiovisuals $i$ informatitzats d'interès general. 
- 7 Sortides realitzades simultàniament el quart dia. Els itineraris programats es reculien en el llibre: VV.AA.: Sortides de camp: Set itineraris per la Catalunya Central. Ed. EUMO, Vic, 1986. Corresponen a: Montserrat (geologia-botànica), Volcans d'Olot (paisatge-geologia), Muntanya de Sal de Cardona (geologia), Parc Natural de Sant Llorenç de Munt (valoració de la infraestructura i possibilitats de trebajl de parc com a eina d'educació), Riera de Balà (estudi interdisciplinari d'una Conca hidrografica), Estany de Banyoles (estudi limnològic enmarcat en l'entorn) i Bellmunt-Vidrà (geológicabotànica).

- Tots els dies restà oberta una Mostra de Recursos Didàctics que pretenia oferir als assistents un recull representatiu del material de l'àrea existent.

- Entre les activitats paral-leles cal destacar l'homenatge ais germans Vilarrúbia, per la seva tasca com a naturalistes, que es plasmà amb la reedició del llibre: Les zoocecidies de les Plantes de Catalunya. A. Vilarrúbia (1986), EUMO Ed, Vic.

Distribució dels assistents per nivells: Mestres cicle inicial (2'37\%), Mestres cicle mitjà $\left(6^{\prime} 47 \%\right)$, Mestres cicte superior $\left(17^{\prime} 46 \%\right)$, Llicenciats $\left(35^{\prime} 78 \%\right.$ ), professors d'universitat (EU i Facultats, 9'48), estudiants de Magisteri $\left(10^{\prime} 34 \%\right)$, estudiants de Biologia $\left(1^{\prime} 94 \%\right)$, afeccionats ( $\left.{ }^{\prime} 82 \%\right)$, escoles de natura $\left(4^{\prime} 96 \%\right)$, formació professional $(5,39 \%)$.

Algunes conclusions a destacar de les ponències, taules rodones i gnups de treballs, són:

- L'experiència anglesa en escoles de natura els ha portat a oferir un treball unitari, programat per ésser realitzat en la seva totalitat en cinc dies; independentment si l'estudi tindrà o no continuitat a les escoles. Valoren: l'observació, la quantització, interrelació i interpretació de dades, a curt i llarg termini. Acumulen dades de tots els estudis realitzats.

+- La interdisciplinarietat es valora com moit positiva perd alhora es constata el poc treball fet en aquest camp a nivell d'ensenyament secundari i universitari $i$ les dificultats que en alguns nivells comporta.

- Els ensenyaments reclamen més protagonisme en la renovació pedagdgica i exigeixen més realisme als «Reformadors oficials" en fer l'estimacio de les possibilitats existents en quan a medis $\mathrm{i}$ formació permanent del professorat.

$\longrightarrow$ Es un fet la necessitat d'integració de les Escoles de Natura en la infraestructura educativa.

- En les EATP del batxillerat, cal que predominin els aspectes pràctics $i$ que la regularització dels continguts no vin. gui fixada per l'Administració sino que respongui a les litquietuts del professorat i a la demanda de l'aiumnat.

- La renovació en l'ensenyament de la Didactica en les Escoles de Mestres hauria de pasar per: a) Preparació i re novacio del professorat de didactica; b) Lligam entre els continguts i llur didàctica; c) Domini dels continguts i les seves metodologies; d) Evitar l'ensenyament tedric de ta didàctica; e) Poten ciar els contactes $i$ interaccions amb les escoles de pràctiques.

La valoració positiva del Sympòsium en ta sessió de cloenda constata la neces. sitat de donar-li continuitat, si be deljmitant els continguts temàtics per cada trobada. Es fixà el II Sympòsium per la tardor de 1987 i recolliren el com. promis de l'organització els professionals de les Terres de Tarragona que s'aplegaran entorn a l'Escola de Mes. tres de Tarragona.

Consol Blach

\section{OLIMPIADAS INTERNACIONA. LES DE FISICA. LA XVII OLIMPIADA}

\section{Inglaterra, julio 1986}

En las Olimpiadas Internacionales de Física compiten estudiantes de la escuela media (general o técnica). Se han celebrado anualmente, con la excepción de los antos 1973 y 1978 , desde 1967 , y el número de países participantes crece continuamente. En la primera olim. piada, organizada por la República Popular de Polonia, participaron 5 paises: Bulgaria, Checoslovaquia, Hungría, Polonia y Rumania. En la olimpiada de 1986, celebrada en Gran Bretana, participaron 21 paises: Austria, Bulgaria, Canadá, Checoslovaquia, China, $\mathrm{Cu}-$ ba, EUA, Finlandia, Gran Bretanta, Holanda, Hungria, Islandia, Noruega, Polonia, RFA, RDA, Rumanía, Suecia, Turquía, URSS y Yugoslavia.

Las Olimpiadas Internacionales de Fisica contribuyen a perfeccionar la en. sehanza de esta ciencia en los diferentes países participantes. En primer lu- gar, uno de los objetivos principales de las Olimpiadas es, como se expresa en sus estatutos, propiciar el desarrollo de los contactos internacionales en la esfera de la enseñanza de la física: e indudablemente, estos contactos y las discusiones entre los guías de los equipos crean condiciones favorables para un amplio intercambio de experiencias y su posterior utilizactón en los respectivos paises.

En segundo lugar, las Olimpiadas establecen cierto nivel de la ensertanza de la física al que aspiran los paises participantes. Este nivei (el cual se ha elevado año tras año) se ha plasmado en los problemas propuestos a los estu. diantes en las diferentes olimpiadas y quedó fijado en el Programa de fisica, adoptado en 1985 en Yugoslavia. Este programa consta de dos partes fundamentales, una teórica y otra práctica. La parte teórica involucra los siguientes temas: Mecánica, Mecánica del Cuerpo Sólido, Hidro y Aeromecánica, Termodinámica y Física Molecular, Oscilaciones y Ondas, Carga Eléctrica y Campo Eléctrico, Corriente y Campo Magnético, Ondas Electromagnéticas, Físicas Cuánticas, Relatividad, Sustancia. La parte práctica supone a la teórica e incluye algunos requisitos adicionales relativos al manejo de instrumentos y el dominio de técnicas de medición y procesamiento de datos.

En tercer lugar, a la participación de los equipos de los diferentes paises en las Olimpiadas Internacionales, genera!mente le precede una serie de etapas de selección y preparación de los estudian. tes. La perspectiva de formar parte de tales selecciones estimula a estudiantes y profesores a lograr mejores resultados y en consecuencia, contribuye a elevar la calidad de la enseñanza.

Cada pais participante en la Olimpiada envia un equipo que normalmente se compone de 5 estudiantes y de 2 guias (profesores de física o especialis. tas en física). Los gujas de todos los paises integran la Comisión Internacional.

Durante la competición los estudiantes deben resolver 3 problemas teóricos y 1-2 problemas prácticos. Los problemas se preparan por representantes del pais sede y la traducción de sus enunciados, de los idiomas de trabajo (inglés y ruso) a los idiomas de los diferentes paises, se realiza por los respectivos guias. El país sede forma también una comisión especial que califica los trabajos de los estudiantes. Por la solución correcta de todos los problemas 
teóricos se asignan 30 puntos y por la de los problemas práticos, 20 puntos.

Los premios se distribuyen del siguiente modo.

Primero se determina la máxima puntuación individual alcanzada en la olimpiada. Primer premio obtienen los estudiantes que hayan acumulado no menos de $90 \%$ de esa puntuación; segundo premio, los que acumulen entre el 78 y el $89 \%$ y tercer premio, los que acumulen entre 78 y el $89 \%$ y tercer premio, los que acumulen entre el 65 y et $77 \%$; los estudiantes que obtengan entre el 50 y el $64 \%$ reciben mención.

De acuerdo con los Estatutos de las Olimpiadas Internacionales de Fisica, el país sede corre con todos los gastos de los participantes, relacionados con el evento.

La XVII Olimpiada Internacional de Física tuvo lugar entre el 13 y el 20 de julio de 1986, en Harrow, suburbio de ta Ciudad de Londres.

Como es tradicional, el Comité Internacional introdujo algunas variaciones en los enunciados de los problemas propuestos y en la puntuación asignada a las diferentes etapas de resolución de los mismos. La competición transcurrió en dos sesiones (de unas $S$ horas cada una) programadas en distintos días, una para los problemas teóricos y otra para los problemas prácticos.

L a complejidad de los problemas de esta olimpiada fue considerable, to cual se puso de manifitesto en que la mayor puntuación individual fue 37,93 puntos de 50 posibles y sólo existieron 4 primeros premios, es decir, sólo 4 estudiantes obtuvieron más de 34 puntos. Los problemas teóricos versaron sobre: interferencia de ondas tuminosas producidas por dos y n rendijas, propagación de ondas sísmicas en la Tierra y oscilaciones de un sistema de a parti. culas y $n$ resortes dispuestos en forma circunferencial; y los problemas prác. ticos sobre: mediciones en los espectros producidos por múltiples refracciones y reflexiones de la luz en gotas de líquidos, y el estudio con ayuda de una microcomputadora de la evolución de un sistema de 25 partículas confinadas en una caja y que interactuan en un plano. Los mejores resultados por paises (extraoficial) los obtuvieron URSS, RLmania, Checoslovaquia y Gran Bretaña.

Además de la competición y las sesiones de trabajo del Comité Internacional, se llevaron a cabo conferencias, excursiones, visitas a importantes centros culturales, y actividades recreativas y deportivas.

El Comité Internacional reafirmó la proposición de celebrar la Olimpiada de 1987 en la República Democrática Alemana. El representante de la RDA expresó la conformidad de su pais e invitó a todos los paises participantes.

Pablo Valdés

Instituto Pedagógico Superior "Varona» (Cuba)

\section{OLIMPIADAS DE QUIMICA DE FRANCIA}

\section{División de Química}

El pasado día 9 de Mayo en la Universidad Politécnica de Valencia nos reunimos para conocer de cerca los orígenes y objetivos de las Olimpiadas de Quimica en Francia, que fueron presentados por el inspirador de éstas M. Borbouteau Chef Division des Relationes Exterieures Scientifiques Elf-Aquitaine.

Asimismo, se informó del funcionamiento, organizacion y resultado generales de las Olimpiadas de Química en Francia durante los cursos 1984-85 y 1985.86 por la Profesora Mme. Daniéle Cros, Professeur de Universitè de Montpelier Directrice du Centre Internacional francophone pour l'Educatión en Chimie.

En últjmo hugar se plantearon las postbilidades de organización en España de las Olimpiadas de Química. Asistieron y participaron en las discusiones representantes de los distintos estamentos relacionados con la Química, Real Sociedad de Quimica, Colegio de Químicos, Profesores de Universidad, Coordinadores de Química de COU, Profesores de Bachillerato y COU, Representantes de los CEP, Representantes de los ICE, Seminarios Didácticos.

Con las Olimpiadas de Quimica se intenta cubrir los siguientes objetivos:

- Establecer una mayor relación entre la ensenanza de la Química a nive! de Bachillerato, la enseñanza universitaria y la Industria Química.

- Motivar al Profesorado para que desarrolle una Metodología diferente de la enseñanza de la Química más experimental y cercana a la Quimica de la vida real.

- Promover el interés del alumnado hacia el estudio de las Ciencias Experimentales.
- Desarrollar nuevos criterios de la Evaluación de los trabajos experimentales a fin de desplazar en eila el peso que en la actualidad tienen los conocimientos teóricos-memoristicos.

- Proyectar una imagen de la Quím: ca que permita valorar los aspectos ampliamente positivos que la Quimica posee en el contexto social y cuitural.

Para conseguir estos objetivos se organizarian unas pruebas sobre temas prefijados (en Francia estos temas fueron Ac-base, Ox-Red, Cinética Química, Química de hidrocarburos y Polimeros). Estos temas son los que los alumnos habían trabajado previamente con sus profesores desde el punto de vista experimental. Como estímulo se establecerian el máximo número de premios posibies a los alumnos participantes en la experiencia. Los concursos seleccionarían los alumnos a nive! de centro, a nivel de distrito universitario y a nive! de Estado.

Consideramos que en el Comité de Or ganización de los mismos deberian participar representantes de la Real Sociedad de Quf́nica, Colegio de QuimicaANOUE, Industria Química, Profesores de Universidad y de Bachillerato para que la Olimpiada de Química pueda romper el divorcio habitual en que se encuentran estos estamentos.

La dífusión-organización podría realizarse a través de los organismos antes citados añadiendo si cabe los Vicerrectorados de Ordenación Académica, CEP, ICE, Inspección Técnica, Subdirección de Perfeccionamiento del Profesorado.

Dada la acogida inịiciai del proyecto la verdadera dificultad para que dichas Olimpiadas tengan lugar, es conseguir una financiación adecuada que a nuestro criterio se podría obtener de la Industria Química Nacional o Extranjera de forma análoga a lo acontencido en Francia.

Si estás interesado en participar en este proyecto dirigete a:

Rafael Llopis Castelló

ICE Universidad Politécnica

División de Química

46022 Valencia

para poder estar informado del curso de las gestiones.

R. Llopis 